\title{
AN INTEGRATED, MULTI-CRITERIA APPROACH BASED ON ENVIRONMENTAL, ECONOMIC, SOCIAL, AND COMPETENCY CRITERIA FOR SUPPLIER SELECTION
}

\author{
RAHMI BAKI*
}

\begin{abstract}
Supplier selection (SS), which is a critical stage of supply chain management (SCM), is no longer evaluated solely from the perspective of traditional criteria, due to increasing environmental problems and ethical concerns. In this study, a multidimensional approach including environmental, economic, social, and competency concepts was proposed to evaluate SS, and an integrated approach based on Best Worst Method (BWM) and fuzzy TODIM (an acronym in Portuguese of Interactive and Multi-criteria Decision Making) techniques was developed. In the developed approach, BWM was used to first obtain the importance level of the criteria and then to rank the suppliers with fuzzy TODIM. The proposed approach was tested on an automotive company in Turkey. The outcomes of the analysis revealed that the most important main criteria for SS are economic (0.377) and environmental criteria (0.290). In addition, the sub-criteria with the highest criteria weight were listed as product cost (0.120), on-time delivery (0.112), quality control (0.094), logistics costs (0.069), management commitment (0.054), and flexibility (0.054). The results of this study offer theoretical and practical outputs to companies that want to improve their SS process, selection of suppliers, and contributions of the researchers working on the topic.
\end{abstract}

Mathematics Subject Classification. 65C20, 90C05.

Received November 2, 2020. Accepted March 11, 2021.

\section{INTRODUCTION}

Growing concerns about climate change, environmental protection, and global warming have led companies to focus on customers' environmental expectations in order to achieve a competitive advantage [4]. Supply Chain Management (SCM), which is a fundamental strategy for companies to obtain reliable and cost-effective products, was evaluated from the perspective of environmental concerns and the Green Supply Chain Management (GSCM) idea was evaluated [20]. GSCM is a concept that encourages environmental thinking and strategies, strengthens environmental awareness, and integrates it into the entire supply chain. The sustaining of GSCM has become a critical issue for companies, as there has recently been strong public awareness of environmental issues [17].

Keywords. Supply Chain Management, supplier selection, Best Worst Method, fuzzy TODIM method, Multi-Criteria Decision Making.

Aksaray University, Aksaray, Turkey.

*Corresponding author: rahmi.baki@hotmail.com 
When managing environmental strategies, organizations should focus not only on the internal supply process, but also on inter-organizational processes [8]. For this reason, companies should cooperate with suppliers who can meet quality and environmental standards, taking into account their needs and expectations. The supplier selection (SS) process, which has an effect on both cost and performance, is one of the critical problems faced by organizations [16]. However, evaluating suppliers is a complex issue which requires the consideration of many factors.

Since SS problems are based on many factors such as cost and quality, they are considered as part of MultiCriteria Decision Making (MCDM). Many researchers with aims of improving the SS processes of companies have conducted studies on the topic, and various MCDM techniques have been used in these projects. However, for those studies, suppliers were generally evaluated with economic and environmental criteria, and little attention was paid to supplier evaluations which take different dimensions into account. In this study, suppliers were evaluated with a four-dimensional structure that included environmental, economic, social, and competency criteria. In addition, considering that the increase in SS research and the use of different MCDMs will improve the knowledge on the subject, an integrated approach was developed in which the Best Worst Method (BWM) and fuzzy TODIM (an acronym in Portuguese of Interactive and Multi-criteria Decision Making) techniques were used together.

Although economic factors have traditionally been taken into account when evaluating supplier performance, companies have recently started to focus more on environmental issues [16]. Although there are studies in the literature whose authors consider environmental criteria to improve the SS process, the subject is rarely approached from social and ethical perspectives and structured models containing these aspects are rarely presented [13]. Supply chain performance can be increased by considering environmental, social, and economic factors together in SS [20]. Moreover, there is no specific study in the automotive sector in which environmental, economic, and social criteria have been evaluated together for SS. In addition, in this study the competency dimension was included (which was not previously tested) as a main criterion in the SS literature. The competence of an alternative was measured by levels of flexibility, innovation, quality control, and R\&D. Thus, in this study, the selection of a supplier of an automobile company operating in Turkey was based on environmental, economic, social, and competency criteria and they were evaluated using a four-dimensional frame containing the concepts.

SS, which is one of the critical stages of SCM, is an MCDM process. In this study, taking into account the multi-criteria nature of SS problems, a multi-criteria approach consisting of two stages was adopted. In the first stage, the importance levels of the criteria considered in SS were determined using BWM. In the second stage, alternative suppliers were ranked using the fuzzy TODIM technique. BWM is a technique based on binary comparisons between the rest of the criteria and the best and worst criteria through a simple optimization model. Compared to current MCDM techniques, the method requires fewer data and time comparisons; it is less complex; and it is easier to implement. In addition, more consistent and reliable results are obtained. BWM is especially useful for obtaining the importance levels of criteria [32].

TODIM is a technique derived from Prospect Theory, in which alternatives are listed according to benefit/cost criteria to capture the bounded rationality of the decision maker in a decision process. The aim of the method is to determine the degree of dominance of alternatives, using the utility function [26]. TODIM is useful because it considers the bounded rationality behavior characteristics of the decision maker [19]. In addition, the fuzzy TODIM technique has been used to overcome problems arising from subjective decision maker preferences. In a review of the literature, no SS research was found in which these two techniques were used together. For these reasons, a two-stage, integrated approach in which BWM and fuzzy TODIM techniques were used together was used in this analysis.

The primary goal of this research was to provide a different perspective on the subject by presenting an effective, original, and integrated approach based on environmental, economic, social, and competency criteria to support the SS of companies. Other objectives included (i) defining and investigating evaluation criteria as the result of a systematic and detailed examination of the SS literature; (ii) providing useful tips for customers and companies by determining the importance levels of the criteria with the comments of experts with experience in 
different areas; (iii) obtaining a comprehensive understanding of SS by incorporating the concept of competence into the proposed model; (iv) proposing a mixed approach using two decision-making techniques together; and (v) testing the proposed model for the SS of an automobile firm in Turkey.

\section{Literature REVIEW}

SCM consists of many stages and requires a potential supplier at each stage [16]. As a result of the SS decision, the costs should be reduced, the quality should be increased, and the company should provide a competitive advantage [5]. The aim of SS is to identify the most effective suppliers in meeting customer needs [13]. Today, environmental concerns have led to more of a focus on alternatives which emphasize green practice initiatives. For this reason, organizations should evaluate their suppliers' environmental stances while examining their performance [12].

Selecting one of the many potential suppliers with varying characteristics is a complicated process involving qualitative and quantitative criteria. MCDM is an effective and appropriate approach for solving this complex problem [1]. Table 1 shows a list of studies in which the authors used MCDM methods for Green Supplier Selection (GSS); it also shows the environmental criteria recommended in the studies. For this part of the study, current studies conducted to improve SS from an environmental perspective and MCDM understanding were included. In the proposed model, the environmental dimension is defined with 10 sub-criteria. These criteria were determined based on these studies in which MCDM techniques were used for GSS.

Shaw et al. [30] focused on the carbon emission problem of an India-based garment company and performed an SS process using the fuzzy AHP (FAHP)/Multi Objective Linear Programming (MOLP) techniques. Govindan et al. [12] analyzed a process that integrates Qualitative Performance Evaluation (QPE) and fuzzy TOPSIS techniques based on the Triple Outline approach for SS. Shen et al. [31] conducted an environmental evaluation of the suppliers of an automobile company and created an overall performance score. Kannan et al. [22] developed an SS framework for an electronics company, focusing on GSS practices. Cao et al. [3] tested an intuitive fuzzy MCDM to select the most suitable supplier based on key elements in the manufacturing process. Rostamzadeh et al. [29] presented a quantitative model to evaluate GSCM indicators and analyzed this model in the SS problem of a laptop manufacturer in Malaysia. Ghorabaee et al. [10] aimed to evaluate suppliers according to environmental criteria and to reduce environmental effects in the supply chain with an approach based on a procedure in which Interval Type-2 Fuzzy Sets (IT2FS) and WASPAS were integrated. Rezaei et al. [28] formed a three-step process of pre-selection, selection, and consolidation for the supply chain in the food industry. Guo et al. [14] evaluated supplier performance in the apparel industry using the Fuzzy Axiomatic Design (FAD) technique. Qin et al. [26] tested the technique developed based on IT2FS applied to a GSS problem. Banaeian et al. [2] applied three MCDM techniques for evaluation of a company's GSS process and compared the results in the environmental management system (EMS) perspective. Wei et al. [32] tested an integrated approach to GSCM, which performs both GSS and order allocation, with real data taken from an electronics firm. Guarnieri and Trojan [13] proposed a model that will enable the selection of suppliers in the textile industry to be evaluated within the perspective of ethical and economic issues. Gupta et al. [16] made evaluations among suppliers operating in the Indian automotive industry using traditional and environmental criteria. Mishra et al. [25] used the WASPAS technique together with fuzzy sets and showed the applicability of this method to GSS problems. Dalić et al. [6] evaluated the suppliers for seven environmental criteria by integrating the fuzzy PIPRECIA and Interval Rough Simple Additive Weighting (IRSAW) methods. Ecer [7] proposed an approach for SS of a home appliance manufacturer, considering environmental concepts and using the AHP and IT2FS methods together. Javad et al. [20] developed an approach to rank steel industry suppliers according to their environmental innovation capabilities. Kumari and Mishra [23] tested the technique developed by using COPRAS and Gray Relational Analysis (GRA) methods on the GSS problem of a manufacturer company in Iran. 
TABLE 1. Methods and criteria used in GSS studies.

\begin{tabular}{|c|c|c|}
\hline Author(s) & Method & Criteria \\
\hline Shaw et al. $[30]$ & FAHP, MOLP & Cost, Quality, Lead time, Emission, Demand \\
\hline Govindan et al. [12] & PS, TOPSIS & Pollution, Consumption, Eco-design, EMS \\
\hline Shen et al. $[31]$ & Fuzzy TOPSIS & $\begin{array}{l}\text { Commitment, Green technology, Eco-design, Green } \\
\text { materials, Consumption, EMS, Environmental train- } \\
\text { ing, Pollution, Image }\end{array}$ \\
\hline Kannan et al. [22] & Fuzzy TOPSIS & $\begin{array}{l}\text { Commitment, Cooperation, Compliance, Certifica- } \\
\text { tion, Green suppliers, Environmental management, } \\
\text { Eco-design, Clean production, Packaging, Clean tech- } \\
\text { nology, Product designs, Unnecessary stock disposal, } \\
\text { Scrap disposal, Waste equipment disposal }\end{array}$ \\
\hline Cao et al. $[3]$ & Fuzzy TOPSIS & $\begin{array}{l}\text { Remanufacturing, Consumption, Reverse logistics, } \\
\text { Waste management, Certification }\end{array}$ \\
\hline Rostamzadeh et al. [29] & VIKOR & $\begin{array}{l}\text { Design, Production, Purchasing, Recycling, Trans- } \\
\text { portation, Warehousing }\end{array}$ \\
\hline Ghorabaee et al. [10] & Entropy, IT2FS, WASPAS & $\begin{array}{l}\text { Pollution, Consumption, Design, EMS, Commitment, } \\
\text { Green technology, Green materials }\end{array}$ \\
\hline Rezaei et al. [28] & BWM & $\begin{array}{l}\text { Compliance on certification, Sustainability } \\
\text { performance }\end{array}$ \\
\hline Guo et al. [14] & FAD & Emission, EMS, Pollution, Consumption \\
\hline Qin et al. [26] & IT2FS, TODIM & $\begin{array}{l}\text { Innovation, Image, Technology, Consumption, EMS, } \\
\text { Quality, Life cycle, Pollution, Training }\end{array}$ \\
\hline Banaeian et al. [2] & TOPSIS, VIKOR, GRA & EMS \\
\hline Wei et al. [32] & BWM, TOPSIS, MOLP & $\begin{array}{l}\text { Environmental performance, Innovation capability, } \\
\text { Green logistic }\end{array}$ \\
\hline Guarnieri and Trojan [13] & AHP, ELECTRE & $\begin{array}{l}\text { Environmental impact, Packaging, Emission, } \\
\text { Hazardous waste, EMS, Projects for environment, } \\
\text { Green image, Diversity, Environmental costs, } \\
\text { Security }\end{array}$ \\
\hline Gupta et al. $[16]$ & $\begin{array}{l}\text { FAHP, TOPSIS, WASPAS, } \\
\text { MAPAC }\end{array}$ & $\begin{array}{l}\text { EMS, Image, Training, Eco-Design, Pollution, } \\
\text { Consumption }\end{array}$ \\
\hline Mishra et al. [25] & WASPAS, VIKOR & Design, EMS, Production, Commitment, Technology \\
\hline Ecer $[7]$ & IT2FS, AHP & Technology, Manufacturing, Management \\
\hline Javad et al. $[20]$ & BWM, Fuzzy TOPSIS & $\begin{array}{l}\text { Collaborations, Environmental investments, Resource } \\
\text { availability, EMS, Design, purchasing, Obligations }\end{array}$ \\
\hline Dalić et al. $[6]$ & Fuzzy PIPRECIA, IRSAW & $\begin{array}{l}\text { Image, Recycling, Pollution, EMS, Green products, } \\
\text { Resource consumption, Green competencies }\end{array}$ \\
\hline Kumari and Mishra [23] & COPRAS, GRA & $\begin{array}{l}\text { Pollution, Supply consumption, Eco-design, Manage- } \\
\text { ment system, Commitment, Green technology, Green } \\
\text { materials, Quality management }\end{array}$ \\
\hline
\end{tabular}

\section{Methods}

The BWM and fuzzy TODIM techniques used in the approach proposed in this section of the study are introduced step by step.

\subsection{Best Worst Method}

BWM is based on paired comparisons among all criteria and the best/worst criteria. Decision makers should specify the most important and least important criteria and make binary comparisons of these and others. The method contains many positive features. First, compared to current MCDM techniques, BWM requires less 
comparison data because it uses only two vectors. Secondly, since fewer comparison data are required, it is less complex, easy to understand, and it saves time. Third, it has a lower inconsistency ratio compared to traditional methods such as AHP [18]. Fourth, it provides reliable results from a structured, pairwise comparison [24]. Fifth, it is very easy to find and revise the reasons for inconsistencies [28]. Finally, using it with other methods does not require a complicated process. This method, which makes a comparison system, is used to specify the weight of all selection criteria [33]. The BWM consists of the steps given below [27].

Step 1. The criteria $\left(c_{n}\right)$ to be evaluated in the decision process are determined.

Step 2. The best and worst criteria are decided. These may be the most/least desirable or the most important criteria. There is no comparison at this step.

Step 3. The relationship between the best criterion and other criteria is stated using a number between 1 and 9. As a result, the best comparison vector for other criteria is obtained as follows:

$$
A_{B}=\left(a_{B 1}, a_{B 2}, \ldots, a_{B n}\right) .
$$

In the equation, $a_{B j}$ shows the option of the best criterion $B$ based on $j$ criteria, and the $a_{B B}$ value will be equal to 1.

Step 4. The relationship between the worst criterion and all criteria is stated using a number between 1 and 9. The worst comparison vector for other criteria is obtained as follows:

$$
A_{W}=\left(a_{1 W}, a_{2 W}, \ldots, a_{n W}\right)^{T} .
$$

In the equation, $a_{J W}$ shows the preference of the worst criterion $W$ based on $j$ criteria. The $a_{w w}$ value will be equal to 1 .

Step 5. The optimal weight values $\left(w_{n}^{*}\right)$ of the criteria are obtained.

The optimal weight for the criteria is $w_{B} / w_{J}=a_{B j}$ and $w_{J} / w_{W}=a_{j W}$ for each $w_{B} / w_{J}$ and $w_{J} / w_{W}$ pair. To fulfill the conditions of all $j$, a solution must be found in which the maximum absolute differences $\left|\frac{W_{B}}{W_{j}}-a_{B j}\right|$ and $\left|\frac{W_{j}}{W_{W}}-a_{j W}\right|$ are minimized. Considering the total conditions and the non-negative states of the weights, the following problem arises:

$$
\begin{aligned}
& \underset{j}{\min \max }\left\{\left|\frac{W_{B}}{W_{j}}-a_{B j}\right|,\left|\frac{W_{j}}{W_{W}}-a_{j W}\right|\right\} \\
& \text { s.t. } \\
& \sum_{j} W_{j}=1 \\
& W_{j} \geq 0 .
\end{aligned}
$$

Equation (3.1) can be converted to equation (3.2).

$\operatorname{Min} \xi$

s.t.

$$
\begin{aligned}
& \left|\frac{W_{B}}{W_{j}}-a_{B j}\right| \leq \xi, \\
& \left|\frac{W_{j}}{W_{W}}-a_{j W}\right| \leq \xi, \\
& \sum_{j} W_{j}=1 \\
& W_{\mathrm{j}} \geq 0 .
\end{aligned}
$$


TABLE 2. Consistency index values.

\begin{tabular}{llllllllll}
\hline \hline$a_{B W}$ & 1 & 2 & 3 & 4 & 5 & 6 & 7 & 8 & 9 \\
\hline Consistency Index $\left(\xi_{\max }\right)$ & 0.00 & 0.44 & 1.00 & 1.63 & 2.30 & 3.00 & 3.73 & 4.47 & 5.23 \\
\hline
\end{tabular}

With the solution to equation (3.2), optimal criteria weights and the $\xi$ value are obtained.

We obtain the value of different values of e by solving various alternatives. The maximum $\xi$ value $\left(\xi_{\max }\right)$ obtained is used to obtain the consistency index (Tab. 2). Then, the consistency ratio is reached through equation (3.3). As the consistency ratio approaches zero, consistency increases and a value below one is considered sufficient.

$$
\text { Consistency Ratio }=\frac{\xi_{\max }^{*}}{\text { Consistency Index }} .
$$

\subsection{Fuzzy TODIM}

TODIM method is a discrete MCDM technique based on Prospect Theory [21]. The method uses a global measure of value that can be calculated by applying Prospect Theory [11]. The logic of the technique is to minimize the inconsistency of the process with the perspective of a binary comparison between criteria. The aim of the method is to specify the degree of dominance of each alternative over the others. The steps of the TODIM process are given below [9].

Step 1. Decision makers $\left(D_{k}\right)$ evaluate the importance level of criteria $\left(C_{l}\right)$ for use in evaluating alternatives $\left(A_{m}\right)$.

Step 2. Criteria scores are compared using the variables $\left(x^{l}, x^{m}, x^{u}\right)$ to calculate the gains and losses of certain alternatives versus others. The distance between two numbers is calculated by equation (3.4).

$$
d\left(\tilde{x}_{i j}, \tilde{x}_{k j}\right)=\sqrt{\frac{1}{3}\left[\left(x_{i j}^{l}-x_{k j}^{l}\right)^{2}+\left(x_{i j}^{m}-x_{k j}^{m}\right)^{2}+\left(x_{i j}^{u}-x_{k j}^{u}\right)^{2}\right]} .
$$

For criterion $C_{j}$, the $G_{i k}^{j}$ value shows the gain and the $L_{i k}^{j}$ value indicates the loss (when $A_{i}$ and $A_{k}$ alternatives are compared) as defined by equations (3.5)-(3.8).

For the gain criterion,

$$
\begin{aligned}
G_{i k}^{j} & = \begin{cases}d\left(\tilde{x}_{i j}, \tilde{x}_{k j}\right) & \tilde{x}_{i j} \geq \tilde{x}_{k j} \\
0 & \tilde{x}_{i j}<\tilde{x}_{k j}\end{cases} \\
L_{i k}^{j} & =\left\{\begin{array}{ll}
0 & \tilde{x}_{i j} \geq \tilde{x}_{k j} \\
-d\left(\tilde{x}_{i j}, \tilde{x}_{k j}\right) & \tilde{x}_{i j}<\tilde{x}_{k j}
\end{array} .\right.
\end{aligned}
$$

For the loss criterion,

$$
\begin{aligned}
G_{i k}^{j} & = \begin{cases}0 & \tilde{x}_{i j} \geq \tilde{x}_{k j} \\
d\left(\tilde{x}_{i j}, \tilde{x}_{k j}\right) & \tilde{x}_{i j}<\tilde{x}_{k j}\end{cases} \\
L_{i k}^{j} & = \begin{cases}-d\left(\tilde{x}_{i j}, \tilde{x}_{k j}\right) & \tilde{x}_{i j} \geq \tilde{x}_{k j} \\
0 & \tilde{x}_{i j}<\tilde{x}_{k j} .\end{cases}
\end{aligned}
$$

Step 3. Matrices are normalized using equations (3.9) and (3.10) to compare the gains and losses of different criteria. Thus, normalized gain $\left(Y_{j}=\left[Y_{i k}^{j}\right]_{m x m}\right)$ and loss matrices $\left(Z_{j}=\left[Z_{i k}^{j}\right]_{m x m}\right)$ are obtained:

$$
Y_{i k}^{j}=\frac{G_{i k}^{j}-G_{J}^{\min }}{G_{J}^{\max }-G_{J}^{\min }}
$$


in which $G_{J}^{\max }=\max \left\{G_{i k}^{j} \mid i, k=1, \ldots, m\right\}, G_{J}^{\min }=\min \left\{G_{i k}^{j} \mid i, k=1, \ldots, m\right\}$

$$
Z_{i k}^{j}=\frac{L_{i k}^{j}-L_{J}^{\max }}{L_{J}^{\max }-L_{J}^{\min }}
$$

in which $L_{J}^{\max }=\max \left\{L_{i k}^{j} \mid i, k=1, \ldots, m\right\}, L_{J}^{\min }=\min \left\{L_{i k}^{j} \mid i, k=1, \ldots, m\right\}$.

Step 4. The criterion with the highest importance is determined as the reference criterion. The transformed importance weights $\left(w_{j r}\right)$ are obtained by using equation (3.11).

$$
w_{j r}=w_{j} / w_{r}
$$

in which $w_{j}=\max \left\{w_{j}\right\}, j=1,2, \ldots, n$.

Then the degrees of dominance for gain and loss are calculated using equations (3.12) and (3.13).

$$
\begin{aligned}
\Phi_{i k}^{j(+)} & =\sqrt{\frac{G_{i k}^{j} w_{j r}}{\sum_{j=1}^{n} w_{j r}}} \\
\Phi_{i k}^{j(-)} & =-\frac{1}{\Phi} \sqrt{\frac{-L_{i k}^{j}\left(\sum_{j=1}^{n} w_{j}\right)}{w_{j}}} .
\end{aligned}
$$

In the equations, $\Phi$ is the loss reduction factor. There must be $0 \leq \Phi_{i k}^{j(+)}<1$ and $\Phi_{i k}^{j(-)} \leq 0$ here. The degrees of dominance for gain and loss $\left(\Phi_{i k}^{j}\right)$ are calculated by equation (3.14). Thus, the dominance degree matrix $\left(\Phi_{j}=\left[\Phi_{i k}^{j}\right]_{m x m}\right)$ for the $C_{j}$ criterion is obtained.

$$
\Phi_{i k}^{j}=\Phi_{i k}^{j(+)}+\Phi_{i k}^{j(-)}
$$

Step 5. The overall dominance degree matrix $\left(\Delta=[i k]_{m x m}\right)$ is calculated by equation (3.15).

$$
\delta_{i k}=\sum_{j=1}^{n} \Phi_{i k}^{j} .
$$

Step 6. Based on the matrix $\Delta$ and using equation (3.16), the overall performance score $\left(\left[A_{i}\right]\right)$ of each alternative is calculated. At this stage, $0 \leq\left(A_{i}\right) \leq 1$ and the greater the $\left(A_{i}\right)$ value of an alternative, the better that alternative is considered.

$$
\delta\left(A_{i}\right)=\frac{\sum_{k=1}^{m} \xi_{i k}-\min _{i=1, \ldots, m}\left\{\sum_{k=1}^{m} \xi_{i k}\right\}}{\max _{i=1, \ldots, m}\left\{\sum_{k=1}^{m} \xi_{i k}\right\}-\min _{i=1, \ldots, m}\left\{\sum_{k=1}^{m} \xi_{i k}\right\}} .
$$

Step 7. Overall performance scores are examined and alternatives are listed.

\section{Proposed MEthod}

Automobile manufacturing companies should start implementing environmental practices in all processes in order to reduce environmental impacts, increase ecological efficiency, and achieve market share targets. Automobile companies' selections of their suppliers according to environmental factors will increase their efficiency and competitive advantage [31]. In this study, a method based on environmental, economic, social, and competence criteria for SS of an automobile firm is presented. 
In the research, an expert board consisting of 7 decision makers with more than 10 years of experience working in an automobile firm was created. Decision makers included a general manager $\left(D_{1}\right)$, a purchasing manager $\left(D_{2}\right)$, a purchasing engineer $\left(D_{3}\right)$, a production manager $\left(D_{4}\right)$, a manufacturing engineer $\left(D_{5}\right)$, a quality manager $\left(D_{6}\right)$, and a product development manager $\left(D_{7}\right)$. While forming the decision-maker group, attention has been paid to ensure that decision-makers have information about suppliers and have a say in supplier selection. In addition, decision makers were asked to make an assessment based on their perceptions about the supplier in question, while evaluating subjective criteria such as reputation and trust. Current studies about SS were examined in detail and the criteria to be used in the study were determined (Tab. 3). Decision makers were asked to evaluate the importance of the criteria in the first phase, and the performance of the alternatives in the second phase. In this study, 5 different alternatives were evaluated. Alternatives are suppliers with institutional characteristics and with whom the company has experience of working together in the past or today. The evaluation process with decision makers took place between July 2020 and September 2020 via email and video conferences. In the analysis process, BWM was used in the first stage and the TODIM technique was used in the second.

Four main criteria (environmental, economic, social, and competence) were used in the study. There are 10 sub criteria under the environmental dimension. Some of these criteria contain similar meanings. For example, the criteria for eco-design, use of green materials and use of green technology may evoke similar meanings for decision-makers at first sight. Here, with the eco-design criterion, it was questioned whether an environmental sensitivity was shown at the design stage of the product. In the use of green material criteria, it is focused on whether recyclable materials are used in addition to the stipulated stages in the design process. In the green technology use criteria, it was evaluated whether technological developments that have environmental concerns were followed. However, emission, management of hazardous waste and green production sub-criteria also have similar meanings. Here, the emission criterion focuses on dangerous gas emissions in the production process. In the hazardous waste management criteria, it is meant to control different wastes other than gas emissions. In the green production criteria, it was evaluated whether an environmental understanding such as low scrap rate or high capacity production is adopted in the production process adopted.

\subsection{Weighting criteria with Best Worst Method}

The weights of the criteria to be used in the evaluation of the suppliers were obtained using the BWM technique. The stages of the applied technique are given below.

Step 1. At this stage, 4 criteria and 24 sub-criteria were determined to compare alternatives (Tab. 3).

Step 2. Decision makers identified the best and worst criteria. While the best criterion was defined as the most important in the selection of the supplier, the worst criterion was the least important. At this stage, the criteria and sub-criteria below each criterion were evaluated separately.

Step 3. Decision makers compared the best criteria preferences for SS with each of the other criteria using a value between 1 and 9 .

Step 4. Decision makers compared the criteria preferences that they considered to be the worst (least important) for SS with each of the other criteria. The experts' evaluations about the main criteria are given in Table 4.

Step 5. By solving the linear model given in equation (3.2), the weights of the criteria were determined. This process was done separately for all decision makers and simple averages of each criterion were taken. Table 5 gives the weights and averages of the main criteria for all decision makers. In addition, using equation (3.3), consistency ratio values were obtained for each decision maker.

Weights of the main criteria of environmental, economic, social, and competence were $0.29,0.377,0.107$, and 0.226, respectively (Tab. 6). By following the same process, the local weights of the sub-criteria were obtained (Tab. 6). Global weights were achieved by multiplying the local weight of the sub-criterion by the global weight of the main criterion of that sub-criterion. 
TABLE 3. Proposed criteria in the study.

\begin{tabular}{|c|c|c|}
\hline Criteria & Sub-criteria & Description \\
\hline \multirow[t]{10}{*}{ Environmental $C_{A}$} & Eco-design $C_{A 1}$ & $\begin{array}{l}\text { Designing products to consume less material/energy, } \\
\text { recyclable and reduce hazardous material use }\end{array}$ \\
\hline & Emission $C_{A 2}$ & Hazardous gas emission produced in production process \\
\hline & $\begin{array}{l}\text { Green management } \\
\text { system } C_{A 3}\end{array}$ & $\begin{array}{l}\text { Having environmental certificates and developing, } \\
\text { implementing and maintaining of environmental poli- } \\
\text { cies/objectives }\end{array}$ \\
\hline & $\begin{array}{l}\text { Green production } \\
C_{A 4}\end{array}$ & $\begin{array}{l}\text { Adoption level of a clean, recyclable, low scrap rate, high } \\
\text { capacity production process }\end{array}$ \\
\hline & $\begin{array}{l}\text { Management com- } \\
\text { mitment } C_{A 5}\end{array}$ & $\begin{array}{l}\text { Commitment to improve and support GSCM practices of } \\
\text { managers }\end{array}$ \\
\hline & $\begin{array}{l}\text { Management of haz- } \\
\text { ardous waste } C_{A 6}\end{array}$ & Supplier's level of controlling hazardous waste \\
\hline & $\begin{array}{l}\text { Resource consump- } \\
\text { tion } C_{A 7}\end{array}$ & $\begin{array}{l}\text { Low raw material and water consumption in the produc- } \\
\text { tion stages }\end{array}$ \\
\hline & Staff training $C_{A 8}$ & Staff training based on environmental targets \\
\hline & $\begin{array}{l}\text { Use of green material } \\
C_{A 9}\end{array}$ & $\begin{array}{l}\text { The level of using recyclable materials in the production } \\
\text { process }\end{array}$ \\
\hline & $\begin{array}{l}\text { Use of green technol- } \\
\text { ogy } C_{A 10}\end{array}$ & $\begin{array}{l}\text { Application of environmental science to protect the envi- } \\
\text { ronment }\end{array}$ \\
\hline \multirow[t]{5}{*}{ Economic $C_{B}$} & $\begin{array}{l}\text { Financial stability } \\
C_{B 1}\end{array}$ & Financial status and stability of the supplier \\
\hline & Logistics cost $C_{B 2}$ & $\begin{array}{l}\text { Sum of transportation costs from the supplier to the cus- } \\
\text { tomer }\end{array}$ \\
\hline & On time delivery $C_{B 3}$ & The ability of the supplier to deliver orders on time \\
\hline & Order fulfilment $C_{B 4}$ & The ability of the supplier to fulfill orders \\
\hline & Product cost $C_{B 5}$ & $\begin{array}{l}\text { Total price of the product, including production, process- } \\
\text { ing and maintenance costs }\end{array}$ \\
\hline \multirow[t]{5}{*}{ Social $C_{C}$} & $\begin{array}{l}\text { Customer satisfac- } \\
\text { tion } C_{C 1}\end{array}$ & $\begin{array}{l}\text { Performance level of the supplier in terms of customer } \\
\text { satisfaction }\end{array}$ \\
\hline & $\begin{array}{l}\text { Intra organizational } \\
\text { collaboration } C_{C 2}\end{array}$ & $\begin{array}{l}\text { Effective execution of discipline and security practices, } \\
\text { providing employees with job opportunities and career } \\
\text { development opportunities }\end{array}$ \\
\hline & Reputation $C_{C 3}$ & $\begin{array}{l}\text { The reputation degree of the supplier in the industry and } \\
\text { past cooperation experience }\end{array}$ \\
\hline & Social service $C_{C 4}$ & $\begin{array}{l}\text { Carrying out activities for the benefit of society in the } \\
\text { fields of education, health and culture }\end{array}$ \\
\hline & Trust $C_{C 5}$ & $\begin{array}{l}\text { Mutual trust relationship between the supplier and the } \\
\text { customer }\end{array}$ \\
\hline \multirow[t]{4}{*}{ Competency $C_{D}$} & Flexibility $C_{D 1}$ & Level of meeting different customer demands \\
\hline & Innovation $C_{D 2}$ & $\begin{array}{l}\text { The supplier's level of adopting new ideas, thoughts and } \\
\text { methods }\end{array}$ \\
\hline & Quality control $C_{D 3}$ & The level of control of the quality of the materials used \\
\hline & $\mathrm{R} \& \mathrm{D}$ level $C_{D 4}$ & $\begin{array}{l}\text { The level of importance given by the supplier to R\&D } \\
\text { activities }\end{array}$ \\
\hline
\end{tabular}


TABLE 4. Expert evaluation of the main criteria.

\begin{tabular}{|c|c|c|c|c|c|c|c|c|c|c|}
\hline \multirow[t]{2}{*}{ Decision Maker } & \multirow[t]{2}{*}{ Best criterion } & \multicolumn{4}{|c|}{ Criteria } & \multirow[t]{2}{*}{ Worst criterion } & \multicolumn{4}{|c|}{ Criteria } \\
\hline & & $C_{A}$ & $C_{B}$ & $C_{C}$ & $C_{D}$ & & $C_{A}$ & $C_{B}$ & $C_{C}$ & $C_{D}$ \\
\hline$D_{1}$ & $C_{B}$ & 3 & 1 & 5 & 6 & $C_{D}$ & 2 & 6 & 2 & 1 \\
\hline$D_{2}$ & $C_{D}$ & 4 & 2 & 5 & 1 & $C_{C}$ & 3 & 3 & 1 & 7 \\
\hline$D_{3}$ & $C_{A}$ & 1 & 2 & 6 & 3 & $C_{C}$ & 5 & 3 & 1 & 3 \\
\hline$D_{4}$ & $C_{B}$ & 1 & 1 & 6 & 3 & $C_{C}$ & 4 & 6 & 1 & 4 \\
\hline$D_{5}$ & $C_{B}$ & 2 & 1 & 2 & 7 & $C_{D}$ & 3 & 6 & 2 & 1 \\
\hline$D_{6}$ & $C_{A}$ & 1 & 3 & 6 & 3 & $C_{C}$ & 5 & 1 & 1 & 2 \\
\hline$D_{7}$ & $C_{B}$ & 2 & 1 & 5 & 2 & $C_{C}$ & 3 & 6 & 1 & 3 \\
\hline
\end{tabular}

TABLE 5. Weights and general averages of criteria for experts.

\begin{tabular}{lllllll}
\hline \hline$D$ & $w_{1}^{*}$ & $w_{2}^{*}$ & $w_{3}^{*}$ & $w_{4}^{*}$ & $\xi^{*}$ & $\mathrm{CR}$ \\
\hline$D_{1}$ & 0.235 & 0.544 & 0.126 & 0.095 & 0.683 & 0.228 \\
$D_{2}$ & 0.156 & 0.277 & 0.073 & 0.494 & 0.838 & 0.364 \\
$D_{3}$ & 0.472 & 0.175 & 0.075 & 0.278 & 1.298 & 0.432 \\
$D_{4}$ & 0.170 & 0.477 & 0.092 & 0.261 & 1.172 & 0.391 \\
$D_{5}$ & 0.262 & 0.478 & 0.188 & 0.072 & 0.541 & 0.145 \\
$D_{6}$ & 0.494 & 0.253 & 0.107 & 0.146 & 0.628 & 0.273 \\
$D_{7}$ & 0.239 & 0.437 & 0.085 & 0.239 & 0.172 & 0.075 \\
$w_{j} / n$ & 0.290 & 0.377 & 0.107 & 0.226 & - & - \\
\hline
\end{tabular}

\subsection{Evaluation of suppliers with fuzzy TODIM}

At this stage of the study, suppliers were evaluated using the TODIM technique. The importance levels of the criteria were taken from the first stage results in which the BWM technique was applied. The steps of the adopted technique are given below.

Step 1. In the approach adopted, criterion weights were obtained from the first stage results.

Step 2. Decision makers evaluated suppliers with linguistic variables. Variables were transformed into fuzzy numbers and their arithmetic averages were taken to create a fuzzy decision matrix. Then, gain and loss matrices were created by using equations (3.5)-(3.8).

Step 3. Using equations (3.9) and (3.10), normalized gain and loss matrices were obtained.

Step 4. By using equation (3.11), the criteria weights obtained in the first phase were converted based on the reference criteria. Then, using equations (3.12) and (3.13), gain and loss dominance degrees were obtained. The value of $\Phi$ was accepted as 1 in equation (3.13) in order to contribute with the real values of the losses on the total score. Finally, the dominance degree matrices for all criteria were calculated using equation (3.14).

Step 5. The overall dominance degree matrix was obtained using equation (3.15). The matrix in question is given below:

$$
\Delta=\left[\begin{array}{lllll}
0 & 0.533 & 4.047 & -54.354 & -21.635 \\
-118.014 & 0 & -18.395 & -140.487 & -97.849 \\
-130.345 & -49.709 & 0 & -150.553 & -112.023 \\
-2.783 & 3.952 & 4.493 & 0 & -1.981 \\
-62.334 & -2.452 & 3.366 & -88.685 & 0
\end{array}\right]
$$

Step 6. Considering the $\Delta$ matrix, the performance scores of all suppliers were calculated using equation (3.16). Accordingly, the performance scores of the suppliers were determined as $\left(A_{1}\right)=0.832,\left(A_{2}\right)=0.152$, $\left(A_{3}\right)=0,\left(A_{4}\right)=1$, and $\left(A_{5}\right)=0.655$. 
TABLE 6. Importance levels of criteria.

\begin{tabular}{llll}
\hline \hline Main criteria & Sub-criteria & Local weights & Global weights \\
\hline$C_{A}(0.290)$ & $C_{A 1}$ & 0.080 & 0.023 \\
& $C_{A 2}$ & 0.052 & 0.015 \\
& $C_{A 3}$ & 0.048 & 0.014 \\
& $C_{A 4}$ & 0.123 & 0.036 \\
& $C_{A 5}$ & 0.185 & 0.054 \\
& $C_{A 6}$ & 0.077 & 0.022 \\
& $C_{A 7}$ & 0.148 & 0.043 \\
& $C_{A 8}$ & 0.167 & 0.048 \\
& $C_{A 9}$ & 0.074 & 0.021 \\
& $C_{A 10}$ & 0.046 & 0.013 \\
\hline$C_{B}(0.377)$ & $C_{B 1}$ & 0.086 & 0.032 \\
& $C_{B 2}$ & 0.182 & 0.069 \\
& $C_{B 3}$ & 0.296 & 0.112 \\
& $C_{B 4}$ & 0.116 & 0.044 \\
& $C_{B 5}$ & 0.319 & 0.120 \\
\hline$C_{C}(0.107)$ & $C_{C 1}$ & 0.260 & 0.028 \\
& $C_{C 2}$ & 0.095 & 0.010 \\
& $C_{C 3}$ & 0.215 & 0.023 \\
& $C_{C 4}$ & 0.099 & 0.011 \\
& $C_{C 5}$ & 0.330 & 0.035 \\
\hline$C_{D}(0.226)$ & $C_{D 1}$ & 0.238 & 0.054 \\
& $C_{D 2}$ & 0.215 & 0.049 \\
& $C_{D 3}$ & 0.416 & 0.094 \\
& $C_{D 4}$ & 0.131 & 0.030 \\
\hline
\end{tabular}

Step 7. According to the obtained performance scores, the performance ranking of the suppliers was $\left(A_{4}\right)>$ $\left(A_{1}\right)>\quad\left(A_{5}\right)>\quad\left(A_{2}\right)>\quad\left(A_{3}\right)$. Accordingly, the most suitable option for the company is $A_{4}$.

\section{Discussion AND CONCLUSIONS}

The decrease in natural resources and increasing environmental pollution have made GSS a critical issue for businesses [20]. In addition, GSS helps to increase productivity and customer satisfaction by saving resources and reducing costs [15]. However, it is not sufficient to solely consider environmental criteria in the SS process. Therefore, in this study, an effective model is proposed for SS with an integrated method, considering different dimensions.

The current literature examining SS and GSS problems was first examined. As a result of this survey, 4 main criteria and 24 sub-criteria were proposed for SS. A case study for an automotive firm operating in Turkey was taken into account. An expert committee consisting of 7 decision makers with expertise in different fields and with more than 10 years of experience was established. A two-step approach was developed in which BWM and fuzzy TODIM techniques were used together so that decision makers could select the best supplier. In the first stage, criteria were evaluated through BWM and criteria weights were determined. In the second stage, 5 suppliers wishing to work with the automotive company were evaluated and ranked using the fuzzy TODIM technique. In addition to providing ease of calculation, low inconsistency, and reliable results, the developed approach has not been used before in studies on SS.

In the first stage, it was determined that economic and environmental criteria were the most critical main criteria for SS. Also, respectively, product cost, on-time delivery, quality control, logistics costs, management commitment, and flexibility were sub-criteria with the highest criterion weights. When analyzed from an environmental 
perspective, it was seen that the most important features sought in a supplier were management commitment, staff training, and resource consumption. According to the economic dimension, which was seen to be the most effective criterion for SS, a supplier should be able to deliver on time as well as keep the product and logistics costs low. While the most important concepts in social terms were trust and customer satisfaction, it was quality control and flexibility in terms of competency.

In the second stage, five alternative suppliers were evaluated in terms of the determined criteria. The suppliers were ranked as $A_{4}, A_{1}, A_{5}, A_{2}$, and $A_{3}$, respectively. The results showed that $A_{4}$ had the highest score, and this alternative stood out through environmental and social criteria. Ranking second, $A_{1}$ stood out with its superiority in terms of economic and social criteria. Being an economical alternative for $A_{5}$ was considered as a positive feature. The unsuccessful perception of $A_{2}$ in environmental and social issues and $A_{3}$ in economic and competency areas prevented them from being accepted as good suppliers. The proposed method is valuable both for suppliers that aim to be a better alternative for companies, and for firms that want to evaluate their suppliers effectively.

\subsection{Contributions and implications}

The main target of the search was to present a systematic and comprehensive model that is compatible with different dimensions in SCM and that can support the decision-making stage. A firm working with outsourcing may adopt this approach in order to identify suitable suppliers. The results obtained in this study may prevent an ineffective supplier from entering the supply chain of the companies. Thus, resource and cost savings will be achieved and negative environmental impacts will be reduced. In addition, as the result of a detailed literature review, presenting an approach that uses environmental, economic, social, and competency criteria together and including the opinions of professionals in the study enriched the theoretical contributions of the results. However, a new and integrated method that can be used in SS has been proposed.

According to the results of the research, the most effective dimension in SS is economy. The sub-criterion with the highest criterion weight was the product cost. Although the increasing environmental and ethical concerns directly affected the SS decisions of the companies, the costs of the products to be purchased were still very important. Therefore, suppliers should keep the product cost, which includes production, processing, maintenance, and warranty costs, at a reasonable level.

Another critical economic criterion is on-time delivery. Suppliers must keep their delivery performance high and comply with pre-defined delivery schedules. However, inexpensive transportation alternatives should be preferred and the cost of transportation should not reach the amount that will be a bother to the customer.

The results show that it is important for companies to choose their suppliers by considering the environmental dimension as well as the economic dimension. First, suppliers' managers must make a commitment to support GSCM practices and the improvement of environmental performance. This commitment will ensure the acceptance of environmental practices and it will likely increase the motivation of employees. Thus, environmental awareness will increase and the development of GSCM applications will be provided. However, effective training on environmental targets should be provided to staff. This will increase the motivation and participation of the staff, who will understand the importance of adopting an environmental approach. In addition, the fact that suppliers keep their resource consumption at a low level in terms of raw materials, energy, and water during the production stage is a feature that brings them to the forefront in the eyes of customers.

The competency dimension comes to the fore, especially with the quality control and flexibility sub-criteria. Suppliers must establish a quality policy and control the quality of materials used in production. Thus, the quality level will increase and competitive advantage will be obtained. In addition, companies should be able to design and manufacture different products within the same planning period. Being able to meet different customer demands and orders in a short time and at a low cost will provide a great advantage to suppliers. Moreover, the trust sub-criterion had the highest importance among the social criteria. Fulfilling the commitments given by the supplier to the customer and gaining the trust of the customer will provide the basis for a long-term business partnership. 
In addition to practical results, the findings from this study offer theoretical clues that will benefit researchers. Recent studies on SS have been examined systematically and in detail, and the criteria proposed in this research have been obtained as a result of this review. This study included economic and social criteria as well. However, the concept of competence, which was not previously recommended in the current literature, was included in the developed approach. In addition, the importance levels of the criteria were determined by taking the opinions of experts who have experience in different fields of study and by adopting a quantitative approach. Researchers working in the field of SS are expected to benefit from the criteria and results proposed in this study.

In this study, an approach that integrates two techniques that are effective in different study areas but not used together in SS problems before is proposed. The aim is to reduce complexity and inconsistency and increase the reliability of the results. It is possible to use the developed approach in solving different SS problems. This study fills a gap in the literature with both the proposed four-dimensional criteria structure and the developed integrated approach.

\subsection{Limitations and further research issues}

Although the suggested approach makes a contribution to the GSS literature, it has some limitations and aspects that can be further developed. First of all, different MCDM techniques can be used for SS in future studies. A committee of experts consisting of 7 different decision makers evaluated the criteria and alternatives in this study. In future studies, experts with careers in different fields can be added to the panel of decision makers and a wider community can be created. In addition, the proposed model can be formulated differently in line with the different goals and expectations of various companies, and it can be added or removed with a new factor.

With minor modifications, the approach developed in this study can be tested in cases involving the supply chains of different industries. In addition, the method can be applied to other problems and management practices in production. Moreover, in future studies, taking into account the interactions among criteria will yield useful results. As a result, more research is needed to define SS criteria and to develop selection methods.

\section{REFERENCES}

[1] A.T. Almeida, Multicriteria decision model for outsourcing contracts selection based on utility function and ELECTRE method. Comput. Oper. Res. 34 (2007) 3569-3574.

[2] N. Banaeian, H. Mobli, B. Fahimnia, I.E. Nielsen and M. Omid, Green supplier selection using fuzzy group decision making methods: a case study from the agri-food industry. Comput. Oper. Res. 89 (2018) 337-347.

[3] Q. Cao, J. Wu and C. Liang, An intuitionsitic fuzzy judgement matrix and TOPSIS integrated multi-criteria decision making method for green supplier selection. J. Intel. Fuzzy Syst. 28 (2015) 117-126.

[4] Y.S. Chen and C.H. Chang, The determinants of green product development performance: Green dynamic capabilities, green transformational leadership, and green creativity. J. Bus. Ethics 116 (2013) 107-119.

[5] H.M.W. Chen, S.Y. Chou, Q.D. Luu and T.H.K. Yu, A fuzzy MCDM approach for green supplier selection from the economic and environmental aspects. Math. Prob. Eng. 2016 (2016).

[6] I. Dalić, Ž. Stević, C. Karamasa and A. Puška, A novel integrated fuzzy PIPRECIA-interval rough SAW model: green supplier selection. Decis. Making: App. Manage. Eng. 3 (2020) 126-145.

[7] F. Ecer, Multi-criteria decision making for green supplier selection using interval type-2 fuzzy AHP: a case study of a home appliance manufacturer. Oper. Res. (2020) 1-35.

[8] B. Fahimnia, J. Sarkis, A. Choudhary and A. Eshragh, Tactical supply chain planning under a carbon tax policy scheme: a case study. Int. J. Prod. Econ. 164 (2015) 206-215.

[9] Z.P. Fan, X. Zhang, F.D. Chen and Y. Liu, Extended TODIM method for hybrid multiple attribute decision making problems. Knowl.-Based Syst. 42 (2013) 40-48.

[10] M.K. Ghorabaee, E.K. Zavadskas, M. Amiri and A. Esmaeili, Multi-criteria evaluation of green suppliers using an extended WASPAS method with interval type-2 fuzzy sets. J. Cleaner Prod. 137 (2016) 213-229.

[11] L.F.A.M. Gomes and L.A.D. Rangel, An application of the TODIM method to the multicriteria rental evaluation of residential properties. Eur. J. Oper. Res. 193 (2009) 204-211.

[12] K. Govindan, R. Khodaverdi and A. Jafarian, A fuzzy multi criteria approach for measuring sustainability performance of a supplier based on triple bottom line approach. J. Cleaner Prod. 47 (2013) 345-354.

[13] P. Guarnieri and F. Trojan, Decision making on supplier selection based on social, ethical, and environmental criteria: a study in the textile industry. Res. Conserv. Recycling 141 (2019) 347-361. 
[14] Z. Guo, H. Liu, D. Zhang and J. Yang, Green supplier evaluation and selection in apparel manufacturing using a fuzzy multi-criteria decision-making approach. Sustainability 9 (2017) 650.

[15] H. Gupta and M.K. Barua, Supplier selection among SMEs on the basis of their green innovation ability using BWM and fuzzy TOPSIS. J. Cleaner Prod. 152 (2017) 242-258.

[16] S. Gupta, U. Soni and G. Kumar, Green supplier selection using multi-criterion decision making under fuzzy environment: a case study in automotive industry. Comput. Ind. Eng. 136 (2019) 663-680.

[17] O. Gurel, A.Z. Acar, I. Onden and I. Gumus, Determinants of the green supplier selection. Proc.-Soc. Behav. Sci. 181 (2015) 131-139.

[18] S. Hendiani, A. Mahmoudi and H. Liao, A multi-stage multi-criteria hierarchical decision-making approach for sustainable supplier selection. Appl. Soft Comput. 94 (2020) 106456.

[19] J. Huang, Z.S. Li and H.C. Liu, New approach for failure mode and effect analysis using linguistic distribution assessments and TODIM method. Reliab. Eng. Syst. Saf. 167 (2017) 302-309.

[20] M.O.M. Javad, M. Darvishi and A.O.M. Javad, Green supplier selection for the steel industry using BWM and Fuzzy TOPSIS: a case study of Khouzestan Steel Company. Sustainable Futures 2 (2020) 100012.

[21] D. Kahneman and A. Tversky, Prospect theory: an analysis of decision under risk. Econometrica 47 (1979) $263-292$.

[22] D. Kannan, A.B.L.S. Jabbour and C.J.C. Jabbour, Selecting green suppliers based on GSCM practices: using fuzzy TOPSIS applied to a Brazilian electronics company. Eur. J. Oper. Res. 233 (2014) 432-447.

[23] R. Kumari and A.R. Mishra, Multi-criteria COPRAS method based on parametric measures for intuitionistic fuzzy sets: application of green supplier selection. Iran. J. Sci. Technol. Trans. Electr. Eng. 44 (2020) 1645-1662.

[24] H.C. Liu, M.Y. Quan, Z. Li and Z.L. Wang, A new integrated MCDM model for sustainable supplier selection under intervalvalued intuitionistic uncertain linguistic environment. Inf. Sci. 486 (2019) 254-270.

[25] A.R. Mishra, P. Rani, K.R. Pardasani and A. Mardani, A novel hesitant fuzzy WASPAS method for assessment of green supplier problem based on exponential information measures. J. Cleaner Prod. 238 (2019) 1-16.

[26] J. Qin, X. Liu and W. Pedrycz, An extended TODIM multi-criteria group decision making method for green supplier selection in interval type-2 fuzzy environment. Eur. J. Oper. Res. 258 (2017) 626-638.

[27] J. Rezaei, Best-worst multi-criteria decision-making method. Omega 53 (2015) 49-57.

[28] J. Rezaei, T. Nispeling, J. Sarkis and L. Tavasszy, A supplier selection life cycle approach integrating traditional and environmental criteria using the best worst method. J. Cleaner Prod. 135 (2016) 577-588.

[29] R. Rostamzadeh, K. Govindan, A. Esmaeili and M. Sabaghi, Application of fuzzy VIKOR for evaluation of green supply chain management practices. Ecol. Indicators 49 (2015) 188-203.

[30] K. Shaw, R. Shankar, S.S. Yadav and L.S. Thakur, Supplier selection using fuzzy AHP and fuzzy multi-objective linear programming for developing low carbon supply chain. Expert Syst. App. 39 (2012) 8182-8192.

[31] L. Shen, L. Olfat, K. Govindan, R. Khodaverdi and A. Diabat, A fuzzy multi criteria approach for evaluating green supplier's performance in green supply chain with linguistic preferences. Res. Conserv. Recycling 74 (2013) 170-179.

[32] H.L. Wei, J.J. Liou, H.S. Wang and Y.S. Tsai, An integrated model for solving problems in green supplier selection and order allocation. J. Cleaner Prod. 190 (2018) 339-352.

[33] S.H. Zolfani, F. Ecer, D. Pamučar and S. Raslanas, Neighbourhood selection for a newcomer via a novel BWM-based revised MAIRCA integrated model: a case from the Coquimbo-La Serena conurbation, Chile. Int. J. Strategic Property Manage. 24 (2020) 102-118. 